\title{
Understanding Advanced Practice Nursing
}

Jennifer Ellis, RN, PhD

Policy Director

Canadian Health Services Research Foundation, Ottawa, ON

Erin Morrison, RN, MHSA

Senior Advisor, Regional Capacity Development Canadian Health Services Research Foundation, Ottawa, ON

The Canadian Health Services Research Foundation (CHSRF) is proud to be one of the supporters of this special issue on advanced practice nursing, which represents several decades of research and programming related to the role of nurses in the health system.

Advanced practice nursing has long been a poorly understood area of health services delivery. It is telling that the most popular issue in CHRSF's Mythbusters series is Myth: Seeing a Nurse Practitioner instead of a Doctor Is Second-Class Care, first published in 2002 and then updated and re-released in 2010 (CHRSF 2010).

Advanced practice nursing has existed in Canada since the 1960s, when nurse practitioners (NPs) were introduced mainly to address shortages of primary care physicians in rural and remote areas. But it is only since the beginning of the twenty-first century that we have seen substantial growth in NP numbers - the NP workforce in Canada doubled from 800 in 2004 to 1,626 in 2008. APNs now work in a wide range of primary and acute care settings. A 2009 Harris/Decima poll of 1,000 Canadians found that $20 \%$ had been treated by an NP, more than $75 \%$ would be comfortable seeing an NP instead of their family doctor, and $80 \%$ thought expanded use of NPs could help control health costs. On the other hand, while NP numbers have been increasing, the opposite has been occurring in the numbers of clinical nurse specialists (CNSs), which, according to a 2010 Canadian Institute for Health Information report (CIHI 2010), dropped from 2,624 to 2,222, a total of 402, between 2000 and 2008 . 
Over the past 10 years, advanced practice nursing has been transformed from a field with sparse research and literature to one with an increasing body of evidence to demonstrate its valuable role. CHSRF has contributed to this evolution through instruments such as the Chair Program in Advanced Practice Nursing. Researchers have also been able to call on resources through the $\$ 25$ million Nursing Research Fund, granted by Health Canada and administered by CHSRF. Clinical Nurse Specialists and Nurse Practitioners in Canada: A Decision Support Synthesis - the report that inspired this special issue - was funded through CHSRF in partnership with Health Canada's Office of Nursing Policy.

Thanks to the work of Dr. Alba DiCenso and Dr. Denise Bryant-Lukosius, and with the support of a strong research team, that report synthesizes an exhaustive body of evidence and culminates with a series of recommendations reached through consultation with decision and policy makers such as professional associations, employers and governments (DiCenso et al. 2010).

Advanced practice nurses (APNs) are starting to make major breakthroughs across Canada; for example, in British Columbia, NPs are being integrated into traditional fee-for-service practices, and Ontario plans to open 26 NP-led clinics across the province by the end of 2012. The growing trend toward use of interdisciplinary teams in primary healthcare in most provinces is also opening the door to more NPs. Projects like this special issue and the decision support synthesis are essential to broaden understanding of NPs' and CNSs' potential. Bryant-Lukosius et al. (2010) highlight the opportunities for greater expansion of the CNS role in long-term care facilities.

The decision support synthesis contained a number of recommendations to advance the role of APNs in Canada, including standardizing APN regulatory and educational requirements and expanding training on interprofessionalism in health professional education programs. Another recommendation was that a pan-Canadian mutlidisciplinary task force involving key stakeholder groups be established to facilitate the implementation of advanced practice nursing roles.

We sincerely hope that this special issue, along with the decision support synthesis, will help to provide the information needed to encourage health services leaders across Canada to effectively integrate advanced practice nursing into their health human resource planning. However, one important area where research is still lacking is a solid economic analysis of the cost-effectiveness of the role of APNs.

CHSRF's vision is "Timely, appropriate and high-quality services that improve the health of all Canadians." The progress in research and health policy regarding the education and deployment of APNs is an excellent example of CHSRF's 
vision being realized. We would like to congratulate the team of researchers who developed this special issue - we believe it will make a valuable contribution to the public dialogue on the role of advanced practice nursing in Canada.

\section{References}

Bryant-Lukosius, D., N. Carter, K. Kilpatrick, R. Martin-Misener, F. Donald, S. Kaasalainen, P. Harbman, I. Bourgeault and A. DiCenso. 2010. “The Clinical Nurse Specialist Role in Canada.” Canadian Journal of Nursing Leadership 23(Special Issue December): 140-66.

Canadian Health Services Research Foundation. 2010. Myth: Seeing a Nurse Practitioner instead of a Doctor Is Second-Class Care. Ottawa, ON: CHSRF. Retrieved November 15, 2010. <http://www.chsrf. $\mathrm{ca} /$ Migrated/PDF/Mythbusters/mythbusters_APN_en_FINAL.pdf $>$.

Canadian Institute for Health Information. 2010. Regulated Nurses: Canadian Trends, 2004-2008. Updated February 2010. Ottawa, ON: CIHI. Retrieved November 15, 2010. <http://secure.cihi.ca/ cihiweb/products/regulated_nurses_2004_2008_en.pdf>

Canadian Nurses Association. 2006. 2005 Workforce Profile of Registered Nurses in Canada. Ottawa, ON: CNA. Retrieved March 2, 2009. <http://www.cna-nurses.ca/CNA/documents/pdf/publications/ workforce-profile-2005-e.pdf>.

DiCenso, A., D. Bryant-Lukosius, I. Bourgeault, R. Martin-Misener, F. Donald, J. Abelson, S. Kaasalainen, K. Kilpatrick, S. Kioke, N. Carter and P. Harbman. 2010. Clinical Nurse Specialists and Nurse Practitioners in Canada: A Decision Support Synthesis. Retrieved November 15, 2010. <http:// www.chsrf.ca/migrated/pdf/10-CHSRF-0362_Dicenso_EN_Final.pdf >. 